\title{
A experiência do microempreendedor individual na ampliação da cobertura previdenciária no Brasil
}

Rogério Nagamine Costanzi; Edvaldo Duarte Barbosa e Hélio Vinícius Moreira Ribeiro

\section{Introdução}

O modelo de previdência social adotado no Brasil teve, desde sua origem, foco voltado para os trabalhadores formais, o que se mantém até hoje, conforme números do Ministério da Previdência Social que apontam que, em 2009, cerca de $80 \%{ }^{1}$ dos contribuintes do Regime Geral de Previdência Social eram empregados. Esse modelo tradicional tem gerado uma cobertura previdenciária parcial que pode ser explicada pela configuração do mercado de trabalho nacional e de sua incompatibilidade parcial com o modelo de seguro social, que não consegue incluir os trabalhadores desempregados, empregados rurais e urbanos sem carteira, assim como praticamente todo o rol de trabalhadores vinculados a atividades autônomas. (JACCOUD, 2009).

O esforço para ampliar a proteção social, via inclusão previdenciária, dessas categorias profissionais marginalizadas começa a ocorrer entre o final da década de 1960 e começo da década de 1970, e foi ampliado com a Constituição Federal de 1988. Ocorre que o sistema previdenciário era, e de certa forma ainda é, 
fortemente ligado à conjuntura do mercado de trabalho, e ficou claro, com a crise dos anos 1980, que a simples inclusão de diferentes categorias profissionais no sistema previdenciário não era garantia plena para o acesso aos direitos sociais previdenciários (RANGEL et al., 2009).

Um grupo que sempre respondeu por parcela relevante da desproteção previdenciária no Brasil é o dos chamados trabalhadores por conta própria, sendo seu nível de proteção inferior até mesmo àquele prevalecente entre os trabalhadores domésticos. Uma proporção muito pequena desse grupo contribui para a Previdência Social, prevalecendo alto nível de informalidade nessa posição da ocupação. Em muitos casos, trata-se de alternativa de sobrevivência ou ocupação de última instância para aqueles que não conseguem se inserir no mercado formal. Nesse contexto, a ampliação da cobertura previdenciária desses trabalhadores por conta própria é uma estratégia necessária e fundamental para expansão da proteção social no Brasil e na maioria dos países da América Latina.

Em função dessa realidade, o Governo Federal do Brasil tentou várias medidas com intuito de ampliar a formalização dos chamados trabalhadores por conta própria: a) a Lei n ${ }^{\circ} 10.666 / 2003$, que alterou a sistemática de recolhimento dos trabalhadores autônomos que prestam serviços a empresas ${ }^{2}$; b) a instituição do Plano Simplificado de Previdência Social (PSPS), por meio da Lei Complementar $n^{\circ} 123 / 2006$, que reduziu a alíquota de $20 \%$ sobre o salário de contribuição para $11 \%$ sobre o salário mínimo, para contribuintes individuais que prestam serviços para pessoas físicas e contribuintes facultativos, ficando, entretanto, excluído o direito à aposentadoria por tempo de contribuição, com direito apenas a aposentadoria por idade no valor de um salário mínimo.

Por fim, no final de 2008, por meio da Lei Complementar n ${ }^{\circ} 128$, de 19 de dezembro de 2008, foi criado o chamado MicroEmpreendedor Individual (MEI), como sendo o empresário individual que tenha auferido receita bruta anual de até $\mathrm{R} \$ 36$ mil e que fosse optante pelo Simples Nacional. O MEI conta com um novo limite de receita bruta anual desde janeiro de 2012, que é de $\mathrm{R} \$ 60$ mil, conforme estabelecido pela Lei Complementar n ${ }^{\circ}$ 139. Na prática, o MEI foi criado como nova faixa dentro do chamado Simples Nacional, a de faturamento mais baixo e, portanto, na base da pirâmide, que já havia sido criado como forma de dar tratamento diferenciado para micro e pequenas empresas. O MicroEmpreendedor Individual foi ainda mais à frente na redução da carga tributária prevista no Simples, de tal sorte que os optantes pelo referido sistema passaram a ter de pagar apenas a contribuição previdenciária de $11 \%$ sobre o salário mínimo e valores fixos de $\mathrm{R} \$ 1,00$ de ICMS e R\$5,00 de ISS. Em abril de 2011, o programa do MEI sofreu nova redução na contribuição à Previdência Social para $5 \%$ do salário mínimo, conforme determinou a Medida Provisória $n^{\circ}$ 529, de 07 de abril de 2011, posteriormente convertida na Lei n ${ }^{\circ} 12.470$. A baixa contribuição à Previdência Social e a isenção dos demais impostos federais são uma tentativa de estimular a formalização por meio de tratamento tributário mais favorável e compatível com a capacidade contributiva do público-alvo. Em pouco tempo, o referido Programa avançou de forma rápida e com grande capilaridade.

Também foi relevante para a rápida expansão do Programa, o processo 
simplificado e desburocratizado de inscrição, bem como o estímulo por meio de benefícios da formalização como: crédito mais barato, emissão de nota fiscal e outros. Na prática, o MEI engloba diferentes agendas governamentais e várias instituições governamentais e não governamentais; trata-se de uma ação de ampliação da proteção social, simplificação e desburocratização das microempresas formalizadas e de dar vantagens àqueles que se formalizarem - bem como processo de fortalecimento de microempreendedores -, passando, inclusive, pela formalização empresarial. Exatamente por englobar diferentes agendas de governo, o programa contou com a participação de diferentes órgãos públicos.

O presente artigo tem como objetivo descrever e, dentro do possível, avaliar a experiência do MEI, e está organizado da seguinte forma: a) na segunda parte é feita a descrição da contribuição previdenciária dos trabalhadores por conta própria, por meio dos dados da Pesquisa Nacional por Amostra de Domicílios (PNAD) do Instituto Brasileiro de Geografia e Estatística (IBGE), para mostrar o precário nível de proteção social prevalecente entre os trabalhadores por conta própria; b) na terceira parte é feita uma descrição da criação do MEI e da evolução das inscrições, bem como da cobertura em termos de cidades; c) na quarta parte é apresentado um perfil do MEI, a partir dos dados cadastrais; d) na quinta parte é feita uma breve análise da evolução da contribuição previdenciária, a partir dos dados da Pesquisa Mensal de Emprego do IBGE. Nesse caso, a análise não pode ser feita a partir de dados da PNAD, tendo em vista que o programa do MEI é muito recente; e) na sexta parte são apresentadas as considerações finais.
Contribuição previdenciária dos trabalhadores por conta própria

Os chamados trabalhadores por conta própria representam um foco extremamente relevante da desproteção social no Brasil e em toda América Latina. Segundo dados da Pesquisa Nacional por Amostra de Domicílios (PNAD) do Instituto Brasileiro de Geografia e Estatística (IBGE) de 2009, de um total de aproxima-

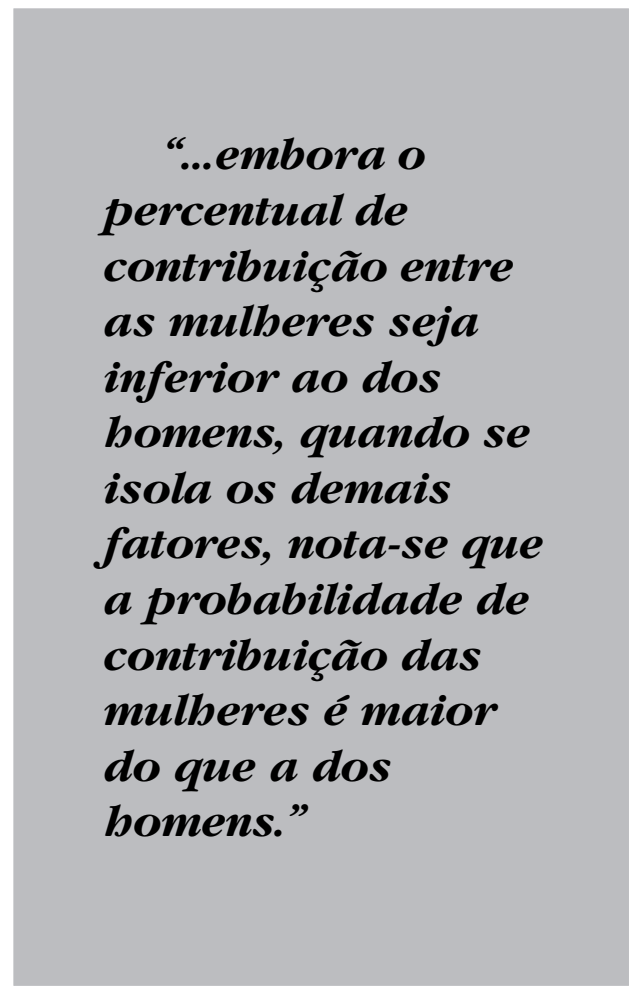

damente 87,5 milhões de trabalhadores ocupados com idade entre 16 e 64 anos, cerca de 38,4 milhões não contribuíam para a Previdência Social, ou seja, 43,9\% do total. O percentual contribuinte, portanto, era de $56,1 \%$.

Entre os diferentes grupos de trabalhadores, pode-se notar, pelos dados do Quadro 1, que entre os empregados, empregadores, trabalhadores domésticos e 
Quadro1: Trabalhadores ocupados de 16 a 64 anos, segundo posição na ocupação e contribuição para o Instituto de Previdência* - Brasil 2009

\begin{tabular}{|c|c|c|c|c|}
\hline $\begin{array}{c}\text { Posição na } \\
\text { ocupação }\end{array}$ & $\begin{array}{c}\text { Com } \\
\text { contribuição } \\
\text { para Previdência }\end{array}$ & $\begin{array}{c}\text { Não } \\
\text { contribuintes }\end{array}$ & Total & $\begin{array}{c}\text { Percentual de } \\
\text { contribuintes } \\
\text { em \% do total }\end{array}$ \\
\hline Empregados & 41.138 .877 & 11.793 .277 & 52.932 .154 & 77,7 \\
\hline $\begin{array}{c}\text { Trabalhadores } \\
\text { domésticos }\end{array}$ & 2.249 .445 & 4.677 .235 & 6.926 .680 & 32,5 \\
\hline $\begin{array}{c}\text { Trabalhadores por } \\
\text { conta própria }\end{array}$ & 3.112 .657 & 14.366 .206 & 17.478 .863 & 17,8 \\
\hline Empregadores & 2.266 .146 & 1.490 .135 & 3.756 .281 & 60,3 \\
\hline Total & $\mathbf{4 9 . 0 8 4 . 9 5 7}$ & $\mathbf{3 8 . 3 6 8 . 4 7 4}$ & $\mathbf{8 7 . 4 5 3 . 4 3 1}$ & $\mathbf{5 6 , 1}$ \\
\hline
\end{tabular}

Fonte: Elaborado pelo autor a partir dos microdados da PNAD/IBGE 2009. * Em qualquer trabalho.

por conta própria, o menor percentual de contribuição para a Previdência Social ocorria justamente para esses últimos: de um total de cerca de 17,5 milhões nessa posição na ocupação, apenas 3,1 milhões eram contribuintes e 14,4 milhões não contribuíam para a Previdência Social. Portanto, o percentual de contribuintes entre os trabalhadores por conta própria caía para $17,8 \%$, sendo o mais baixo entre os grupos analisados - inferior, inclusive, ao nível prevalecente entre os trabalhadores domésticos. Portanto, pode-se afirmar grosso modo que de cada 5 trabalhadores por conta própria, apenas 1 contribui para a Previdência Social. Do total de 38,4 milhões de trabalhadores que não contribuíam para a instituição mencionada, cerca de 14,4 milhões eram trabalhadores por conta própria e, portanto, esse grupo respondia por $37,4 \%$ do total de não contribuintes.

Uma análise econométrica, por meio de uma regressão logística binária, também confirma que os trabalhadores por conta própria têm menor propensão a contribuir. Foi considerada como variável dependente a contribuição (sendo 1 para contribuintes e 0 para não contribuintes) e como variáveis independentes: a) renda do trabalho em salários mínimos; b) dummy de sexo, sendo 1 para homem e 0 para mulher; c) dummy de posição na ocupação, sendo 1 para trabalhador por conta própria e 0 para as demais ocupações; d) idade.

O Quadro 2 mostra que quanto maior o nível de renda e maior a idade - mantidos constantes ou isolados os demais fatores, como sexo e posição na ocupação -, aumenta a probabilidade de contribuição para a Previdência. Portanto, considerando adultos do mesmo sexo, da mesma idade e na mesma posição na ocupação, quanto maior o nível de renda deles, maior será a probabilidade de contribuição.

De forma inversa, ser homem em relação a ser mulher, e ser trabalhador por conta própria em relação à outra posição na ocupação (empregado, empregador, servidor público ou trabalhador doméstico), mantidos constantes ou isolados os 
demais fatores (renda e idade), implica uma diminuição da probabilidade de contribuição.

Cabe destacar que embora o percentual de contribuição entre as mulheres seja inferior ao dos homens, quando se isola os demais fatores, nota-se que a probabilidade de contribuição das mulheres é maior do que a dos homens. O menor nível de contribuição, portanto, é resultado de outros fatores, em especial o menor nível de renda.

A análise também demonstrou a menor probabilidade de contribuição dos trabalhadores por conta própria em relação às demais posições na ocupação. Portanto, um trabalhador por conta própria, com a mesma renda, idade e sexo de um trabalhador que não é do tipo conta própria, terá probabilidade menor de contribuição do que esse último.

\section{Instituição e evolução do MEI}

Certamente, um dos principais atrativos do MEI é seu baixo custo em termos de formalização e de obtenção da proteção previdenciária. Esse programa, entre 2008 e abril de 2011, era similar ao Plano Simplificado de Previdência Social (PSPS), do ponto de vista da contribuição monetária para a Previdência Social (11\% do salário mínimo), mas há diferenças entre ambas as iniciativas. As duas medidas são formas de inclusão previdenciária via incentivos econômicos, sendo o programa do MEI classificado como incentivos voltados para as empresas e o do PSPS como incentivos voltados para os indivíduos (RANGel et al., 2009).

A inscrição do MEI se dá de forma extremamente simplificada, por meio da Internet $^{3}$, e gera, de forma imediata, a abertura de uma empresa para o trabalhador por conta própria informal, com direito a CNPJ e alvará de funcionamento provisório por 180 dias, que, no caso de nenhuma ação da prefeitura, torna-se definitivo. No Plano Simplificado, o trabalhador continua sendo uma pessoa física, enquanto no MEI ele se torna pessoa jurídica formal: o Plano Simplificado está voltado à prestação de serviços para pessoa física e o MEI pode prestar serviços para pessoa jurídica.

Houve diferenças importantes na implementação das duas políticas, com uma postura mais agressiva do MEI em termos de mobilização e publicidade. Essas diferenças explicam a evolução positiva

Quadro 2: Regressão logística binária da probabilidade de contribuição para Previdência Social segundo determinadas características dos trabalhadores ocupados de 16 a 64 anos - Brasil 2009, PNAD/IBGE

\begin{tabular}{|l|c|c|c|}
\hline Variável & $\begin{array}{l}\text { Estimativa do } \\
\text { Coeficiente B }\end{array}$ & $\begin{array}{c}\text { Nivel de } \\
\text { Significância }\end{array}$ & Exp (B) \\
\hline $\begin{array}{l}\text { Renda em salário } \\
\text { mínimo }\end{array}$ & $+0,37087$ &, 000 &, 961 \\
\hline Dummy de sexo & $-0,03995$ &, 000 &, 071 \\
\hline $\begin{array}{l}\text { Dummy de posição } \\
\text { na ocupação }\end{array}$ & $-2,63904$ &, 000 & 1,009 \\
\hline Idade & $+0,00849$ &, 000 &, 941 \\
\hline Constante & $-0,06076$ &, 000 & \\
\hline
\end{tabular}

Fonte: Elaborado pelo autor a partir dos microdados da PNAD/IBGE 2009. 
e rápida do MEI vis-à-vis o Plano Simplificado.

Um ponto positivo do MEI é o fato de este integrar diferentes agendas de governo e, por isso mesmo, contemplar distintas ações de vários órgãos federais, como:

a) o Ministério da Previdência Social, pelo seu caráter de ampliação da cobertura previdenciária e da proteção social aos trabalhadores por conta própria, que possuem nível de proteção inferior até mesmo ao dos trabalhadores domésticos e representam contingente grande do total de desprotegidos e não contribuintes (quase $40 \%$ do total de não contribuintes);

b) o Ministério do Desenvolvimento, Indústria e Comércio, mais especificamente a Rede Nacional para a Simplificação do Registro e da Legalização de Empresas e Negócios (Redesim), que tem como objetivo a simplificação e desburocratização do processo de abertura de empresas no país, tendo sido criada pela Lei $\mathrm{n}^{\circ} 11.598 / 2007$ e regulamentada pelo Decreto $\mathrm{n}^{\circ}$ 6.884/ 2009, que ganhou mais força com a criação do MEI;

c) o Serviço Brasileiro de Apoio às Micro e Pequenas Empresas (Sebrae);

d) a Secretaria da Receita Federal do Brasil, tendo em vista que o MEI foi criado no âmbito do Simples Nacional.

Portanto, a forte integração entre as agendas de governo - fato não ocorrido com o PSPS -, favoreceu a divulgação do MEI e a consequente aceitação e adesão ao programa. A ampliação da cobertura previdenciária, simplificação e desburocratização para formalização de microempreendedores informais e fortalecimento das microempresas acabou sendo um fator que favoreceu a evolução do MEI, pois houve sinergia de ações de diferentes órgãos.

Esse exemplo mostra que a integração de ações de diferentes órgãos federais é sempre um desafio do ponto de vista das políticas públicas e que a convergência de interesses de diferentes órgãos em relação a uma determinada política pode ser um fato que ajuda no seu sucesso.

Além do tratamento tributário diferenciado e mais favorável, inclusive no âmbito do Simples Nacional, da simplificação e da desburocratização, outro ponto que parece extremamente importante é o esforço do governo federal no sentido de criar benefícios para a formalização. Entre as vantagens que podem ser citadas estão:

a) possibilidade de emissão de nota fiscal, o que facilita vendas ou prestações de serviços que só são possíveis com emissão de nota fiscal;

b) acesso a crédito como pessoa jurídica em melhores condições do que o crédito normalmente acessado como pessoa física, com altas taxas de juros;

c) acesso facilitado a contadores que, em troca, tiveram enquadramento alterado, de forma favorável, no âmbito do Simples, com o compromisso de darem apoio aos microempreendedores.

Como pode ser visto no Gráfico 1, no final de janeiro de 2010 as inscrições do MEI totalizavam cerca de 77 mil. O ano de 2010 terminou com 809 mil inscrições. No final de março de 2011, esse número havia aumentado para 1.280.000 inscrições. No final de dezembro de 2011 foram registradas 1.895.533 inscrições. Haviam sido atingidas 2.115.546 inscrições no final de fevereiro de 2012. No dia 4 de março, as inscrições já estavam em 2.126.778. O Plano Simplificado, que foi criado em 2006-2007 e possibilita uma contribuição mensal de 11\% do salário mínimo, contabilizou, em dezembro de 2011, em torno de 163 mil recolhimentos de contribuintes individuais e $100 \mathrm{mil} \mathrm{de}$ segurados facultativos. 
Como dito anteriormente, apesar dos importantes avanços obtidos pelo MEI, certamente ainda restam desafios, riscos, cuidados e problemas que precisam ser equacionados. Um dos cuidados necessários em relação ao MEI é o de que o programa não seja utilizado como instrumento para "mascarar" relações de emprego, tendo em vista que sua legislação permite prestação de serviços para pessoa física e jurídica. Exatamente para amenizar esse risco, não são todas as ocupações que podem ser inscritas no MEI, sendo que são permitidas 467 ocupações definidas segundo a Resolução n ${ }^{\circ} 58$, do Comitê Gestor do Simples Nacional (CGSN), de 27 de abril de 2009, com as alterações posteriores, sendo, em geral, ocupações mais típicas de autônomos.

Além disso, o artigo 18-B da Lei Complementar $\mathrm{n}^{\circ} 123 / 2006$, com a redação dada pela Lei Complementar $\mathrm{n}^{\mathrm{o}} 128$, mantinha para a empresa contratante de serviços executados por intermédio do MEI - em relação a esta contratação -, a obrigatoriedade de recolhimento da contribuição de $20 \%$ para a Previdência Social nos casos de serviços de hidráulica, eletricidade, pintura, alvenaria, carpintaria e de manutenção ou reparo de veículos.

Aparentemente, não está havendo substituição de emprego por MEI em larga escala, tendo em vista a expressiva geração de empregos formais observada em 2010: a) os dados do Cadastro Geral de Empregados e Desempregados (Caged) apontou a criação de respectivamente 2,5 e 1,9 milhões de empregos com carteira de trabalho assinada em 2010 e 2011; b) segundo os dados da Relação Anual de Informações Sociais (Rais) foram gerados 2.860.809 empregos formais, sendo que 2.590.377 eram empregos celetistas em

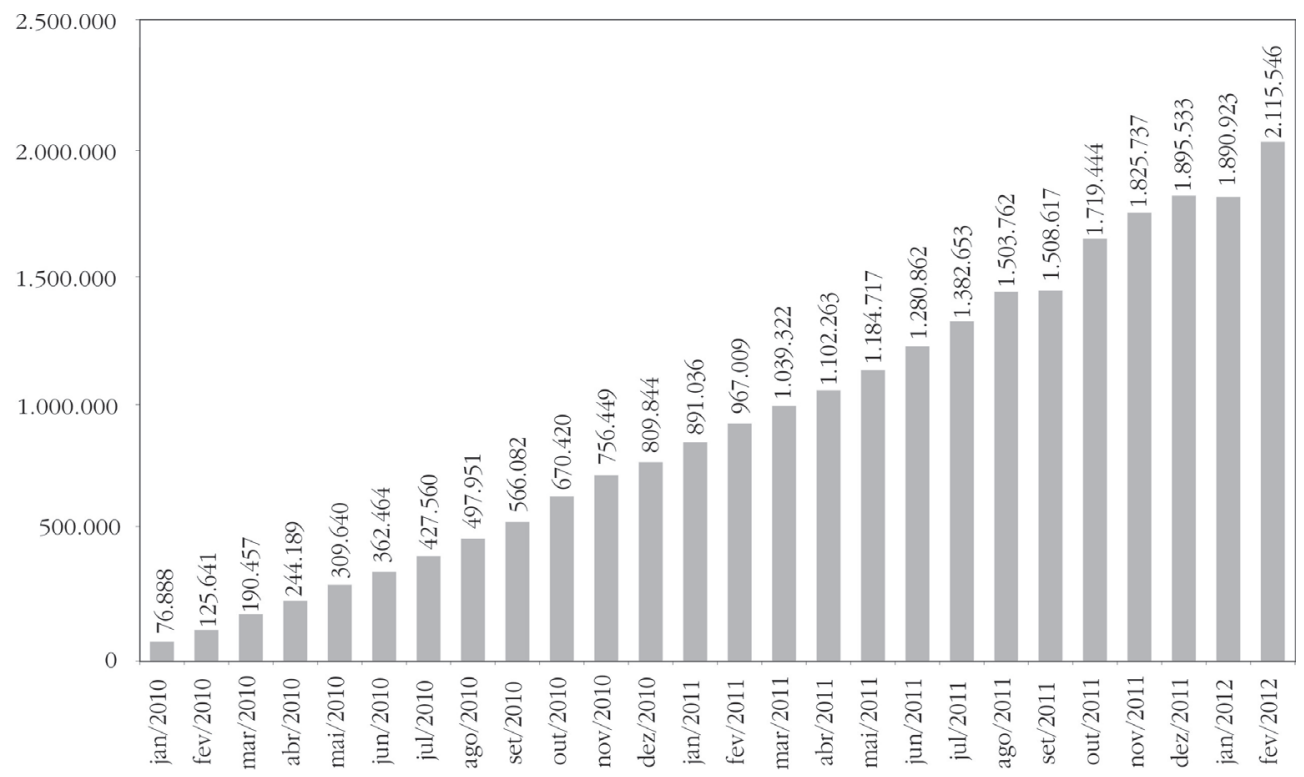

Fonte: Receita Federal - Simples Nacional

Gráfico 1: Evolução do MEI, janeiro de 2010 a dezembro de 2011 
2010. Esses dados, embora não afastem por completo a possibilidade de substituição mascarada de emprego por MEI, certamente são indícios de que isso não tenha ocorrido em larga escala.

Outro desafio diz respeito à necessidade de avançar na simplificação das obrigações impostas ao MEI, que tendem a ser as mesmas impostas às pessoas jurídicas do país. Embora a legislação defenda o tratamento diferenciado, na prática algumas das obrigações típicas de uma empresa mais estruturada - e seus respectivos custos acabaram sendo transferidas ao MEI.

É obvio que o processo de inscrição do MEI foi bastante simplificado, sendo a inscrição feita pelo Portal do Empreendedor em um tempo bastante curto, com exigência de poucas informações, sendo que no final o MEI sai com cadastro no CNPJ e o respectivo número, e um Certificado da Condição de MicroEmpreendedor Individual (CCMEI) que funciona como alvará de funcionamento provisório por um período de 180 dias. Este, no caso de não manifestação do município, tornase efetivo para atividades que não são de alto risco. O pagamento unificado dos poucos impostos mensais (Previdência Social, ICMS e/ou ISS) se dá com a geração de uma guia única e integrada de DAS (Documento de Arrecadação do Simples Nacional) emitida no próprio site. Portanto, o processo de simplificação e desburocratização foi fundamental para a evolução positiva do MEI e reduziu o custo em termos de tempo despendido com obrigações burocráticas.

Contudo, ainda restam desafios em termos de simplificação. Em primeiro lugar, o MEI é uma pessoa jurídica e, como tal, tem várias das obrigações acessórias de qualquer pessoa jurídica normal. Embora a legislação o tenha desobrigado de fazer a declaração "negativa"4 de Guia de Recolhimento do Fundo de Garantia do Tempo de Serviço e Informações à Previdência Social (GFIP) e da Relação Anual de Informações Sociais (Rais) ${ }^{5}$, o MEI precisa declarar GFIP, Rais e o Cadastro Geral de Emprego e Desemprego (Caged), no caso de ter empregado, em uma significativa sobreposição de informações. O MEI, no caso de ter empregado, terá que declarar a mesma informação em três instrumentos diferentes para distintas instituições do governo federal. Para complicar, cumprir essas obrigações não é fácil do ponto de vista operacional, quase sempre implicada a contratação de um contador, o que eleva de maneira considerável o chamado custo da formalização. No âmbito da Receita Federal está em desenvolvimento uma declaração unificada de previdência, uma trabalhista e uma do FGTS, no projeto denominado de "folha digital", conforme estabelecido pela Lei Complementar no 139.

Outra linha importante na evolução do MEI é trabalhar nos benefícios potenciais da formalização. Esse aspecto é muito importante porque, do ponto de vista meramente tributário, a competição com a informalidade é muito difícil, pois a formalização sempre implica deixar de pagar zero de impostos e taxas referentes à atividade por conta própria. Nesse contexto, é fundamental não apenas que a carga tributária seja condizente com a capacidade contributiva desses trabalhadores por conta própria, mas também que esse trabalhador tenha benefícios pela formalização.

Uma primeira vantagem $\mathrm{da}$ formalização é que o MEI passa a poder emitir nota fiscal e há inúmeros casos de compradores que a realizam apenas se houver emissão da referida nota. Além disso, as instituições financeiras federais 
oficiais, como a Caixa Econômica Federal, Banco do Brasil, Banco do Nordeste e Banco da Amazônia, criaram linhas especiais de crédito para o MEI. Importante reforçar que muitos daqueles que se formalizaram, na realidade já tinham acesso a crédito, mas como pessoa física e com taxas de juros elevadas. As linhas de crédito criadas foram para pessoas jurídicas e com taxas de juros mais baixas. A título de exemplificação, passou a haver a possibilidade de acesso a crédito de até R $\$ 15$ mil para o MEI, por meio do Fundo Constitucional de Financiamento do Centro-Oeste (FCO), com taxa de juros subsidiada de 6,75\% ao ano, no âmbito do Programa de FCO Empresarial de Apoio aos Microempreendedores Individuais (MEI) e às Micro e Pequenas Empresas (MPE) ${ }^{6}$. Claro que, mais que a mera criação formal das linhas, é essencial que estas tenham boa execução, pois não seria a primeira vez em que há criação de uma linha oficial sem boa execução na prática.

Um levantamento realizado pela Caixa Econômica Federal mostrou que cerca de 408 mil MicroEmpreendedores Individuais já eram clientes da referida instituição, mas como pessoa física. Portanto, existe um grande trabalho de transferir este público, que em geral já é cliente de instituições como pessoa física, para linhas de pessoa jurídica, em que a taxa de juros, em geral, é menor.

Certamente, ainda há espaço para novas ações, no sentido de trabalhar os benefícios da formalização, como acesso à qualificação e a mercados. Os MicroEmpreendedores Individuais também passam a contar com o apoio do Sebrae.

Outro problema em relação ao MEI é uma alta taxa de inadimplência. Embora a referida taxa esteja em patamar similar ao das faixas acima do MEI no âmbito do
Simples Nacional, tal fato merece ser analisado com profundidade. Em parte, o fato da inscrição no MEI ser tão simplificada e tão fácil pode estar gerando inscrições de pessoas sem o devido conhecimento ou perfil adequado. A inadimplência pode também estar relacionada com a instabilidade da renda dos trabalhadores por conta própria. De qualquer forma, mesmo descontada a inadimplência, ainda há muitos casos de microempreendedor individual

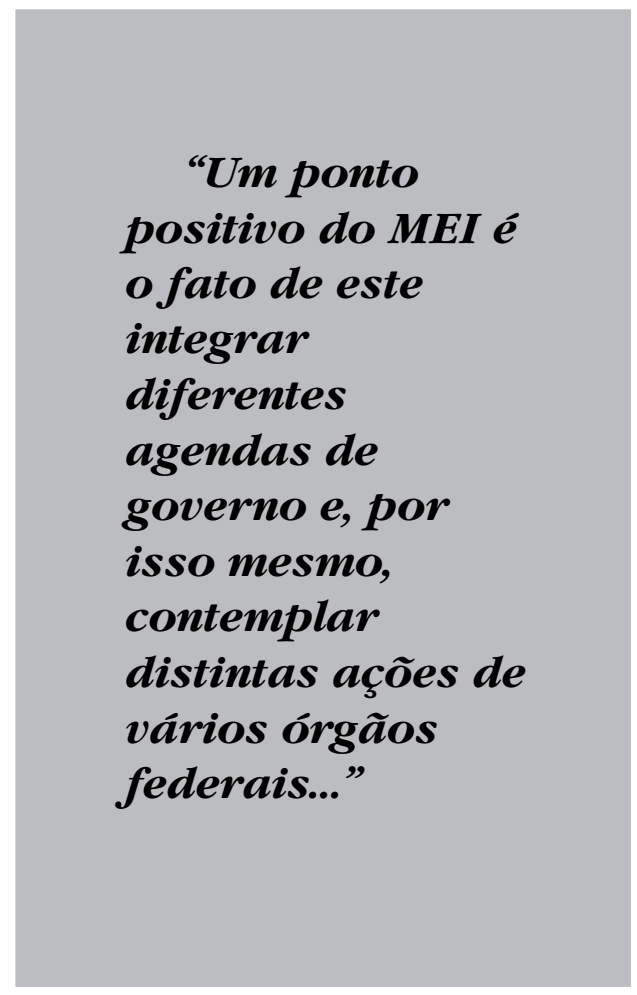

pagando a Previdência Social, o que demonstra que o programa tem impacto realmente significativo.

Contudo, é preciso deixar claro que não necessariamente toda inscrição é uma formalização, podendo ser uma migração de um contribuinte individual que pagava pela regra normal $(20 \%$ do salário de contribuição), ou mesmo no Plano Simplificado 
(11\% do salário mínimo), para o MEI (5\% do salário mínimo), fato que também pode ter ocorrido no âmbito do Plano Simplificado, ou algum outro tipo de transição. É necessário um estudo do passado contributivo das pessoas que migraram, para precisar quanto das inscrições feitas no MEI é efetivamente formalização de trabalhadores por conta própria. Outra possibilidade é que o MEI poderia estar substituindo emprego sem carteira de trabalho, aspecto que será discutido posteriormente.

Talvez, em função da inadimplência não apenas em função dela aparentemente -, mas também por uma possível avaliação de que $11 \%$ do salário mínimo poderia ser um valor elevado para o público beneficiário potencial, foi reduzida a contribuição previdenciária do MEI de 11\% para 5\% do salário a partir da competência de maio de 2011, por meio da Medida Provisória no 529/2011.

A referida redução deve trazer benefícios do ponto de vista da ampliação da proteção social, da cobertura previdenciária e formalização de trabalhadores por conta própria. Contudo, a medida também aumenta o risco, que já existia, de substituição, de forma mascarada, de uma relação de emprego por MEI. Desse ponto de vista, teria sido mais recomendável a redução para 8\%, de forma manter paridade com a contribuição do segurado empregado, que varia de $8 \%$ a 11\%. Ademais, a referida Medida Provisória reduziu para 5\% a contribuição do MEI, mas manteve em 11\% a do Plano Simplificado, de tal forma que pessoas com mesmo direito, em termos de benefício previdenciário, possuem contribuições diferenciadas. Certamente, a medida vai estimular a migração de inscritos no Plano Simplificado para o MEI.

Além disso, embora a medida seja positiva do ponto de vista da inclusão previdenciária, ampliou o desequilíbrio atuarial implícito, que precisa ser discutido no futuro.

Para que se possa compreender melhor: atualmente, com a contribuição de 5\% do salário mínimo e carência de 15 anos na aposentadoria por idade, um trabalhador poderia se aposentar pagando (sem aplicar taxa interna de retorno ou taxa de juros) $\mathrm{R} \$ 5.598$, mas receberia proventos, a partir da atual expectativa de sobrevida para um homem de 65 anos, de cerca de R\$ 122 mil. Nesse contexto, há de se afirmar que a definição da alíquota de 5\% foi estabelecida sem qualquer lógica atuarial, o que não é o ideal quando se trata de uma contribuição previdenciária.

\section{Perfil do MEI}

A partir do cadastro de informações do Ministério do Desenvolvimento, Indústria e Comércio Exterior (MDIC), ${ }^{7}$ foi feito um levantamento do perfil do MEI, com o registro das inscrições realizadas no Portal do Empreendedor, em uma posição que contava com 1,7 milhão de registros. Cabe destacar que são poucas as informações pedidas por ocasião do cadastramento.

Considerando a questão do gênero, de um total de 1.683 .132 registros com informações, 773.870 eram do sexo feminino (46,0\% do total) e 909.262 do masculino (54,0\% do total). Essa predominância do sexo masculino entre os inscritos no MEI é uma realidade no Brasil, como pode ser visto no Quadro 3. A predominância de homens também ocorre em todas as unidades da federação.

A predominância masculina pode estar refletindo, na realidade, a própria predominância de homens entre os trabalhadores por conta própria não contribuintes e, portanto, a análise deve levar em consideração o perfil do público beneficiário potencial. 
Quando se aplicam os filtros nos microdados da PNAD - de trabalhadores por conta própria que não contribuem para previdência, que não são de atividade agropecuária (pois o MEI não abriga ocupações do referido setor, sendo primordialmente urbano) e que tem renda menor ou igual a $\mathrm{R} \$ 3$ mil por mês ( $\mathrm{R} \$ 36$ mil ano) -, chega-se a um público potencial menor, de cerca de 11,5 milhões, sendo 6,8 milhões homens e 4,7 milhões mulheres.

Portanto, é natural que a maior parte dos inscritos seja homens, tendo em vista que o público potencial é predominantemente masculino. Contudo, fazendo as inscrições pelo público potencial, o impacto teria sido maior entre as mulheres do que entre os homens (ver Quadro 4).

Do ponto de vista da idade, a análise dos 1.683.132 casos apontou para uma idade média dos MicroEmpreendedores Individuais, na data de inscrição, de cerca de 36,4 anos, uma mediana de 35 anos e uma moda de 29 anos. O quartil inferior foi de 27 anos (25\% dos MEI têm até 27 anos) e o quartil superior, de 45 anos (apenas $1 / 4$ dos MEI têm 45 anos ou mais).

$\mathrm{Na}$ análise por sexo, não se observa muita diferença etária entre mulheres e homens, tendo em vista que o primeiro grupo apresentava idade média de 36,7 anos

Quadro 3: Quantidade de MEI e distribuição percentual, segundo sexo e região

\begin{tabular}{|c|c|c|c|c|c|c|c|c|}
\hline \multirow[t]{2}{*}{ Região } & \multicolumn{2}{|c|}{ Feminino } & \multicolumn{2}{|c|}{ Masculino } & \multicolumn{4}{|c|}{ Total } \\
\hline & Quant. (A) & $\%(\mathrm{~A} /$ Brasil $)$ & Quant. (B) & $\%$ (B/Brasil) & Quant. (C) & $\%(\mathrm{~A} / \mathrm{C})$ & $\%(B / C)$ & $\%(\mathrm{C} /$ Brasil) \\
\hline Centro-Oeste & 72.002 & 9,3 & 87.645 & 11,3 & 159.647 & 45,1 & 54,9 & 9,5 \\
\hline Nordeste & 170.714 & 22,1 & 200.259 & 25,9 & 370.973 & 46,0 & 54,0 & 22,0 \\
\hline Norte & 50.437 & 6,5 & 62.514 & 8,1 & 112.951 & 44,7 & 55,3 & 6,7 \\
\hline Sudeste & 412.555 & 53,3 & 479.102 & 61,9 & 891.657 & 46,3 & 53,7 & 53,0 \\
\hline Sul & 68.162 & 8,8 & 79.742 & 10,3 & 147.904 & 46,1 & 53,9 & 8,8 \\
\hline Brasil & 773.870 & 100,0 & 909.262 & 100,0 & 1.683 .132 & 46,0 & 54,0 & 100,0 \\
\hline
\end{tabular}

Fonte: Elaborado pelo autor a partir de dados do Serpro e MDIC.

Quadro 4: Distribuição do público potencial e das inscrições do MEI segundo sexo

\begin{tabular}{|l|c|c|c|}
\hline Sexo & $\begin{array}{c}\text { Público Potencial do MEI segundo } \\
\text { microdados da PNAD/IBGE 2009 } \\
\text { (a) }\end{array}$ & $\begin{array}{c}\text { Inscrições Efetivas } \\
\text { (b) }\end{array}$ & $\begin{array}{c}\text { (b) / (a) em } \\
\text { \% }\end{array}$ \\
\hline Homens & 6.802 .210 & 909.262 & 13,37 \\
\hline Mulheres & 4.707 .202 & 773.870 & 16,44 \\
\hline Total & $\mathbf{1 1 . 5 0 9 . 4 1 2}$ & $\mathbf{1 . 6 8 3 . 1 3 2}$ & $\mathbf{1 4 , 6 2}$ \\
\hline
\end{tabular}

Fonte: Elaborado pelo autor a partir de dados do Serpro, MDIC e microdados da PNAD/IBGE 2009. 
e o segundo, de 36,2 anos. A idade mediana dos homens e das mulheres era de 35 anos. Portanto, de modo geral, pode-se dizer que o público masculino predominante não é de idades avançadas, pelo contrário: cerca de $1 / 4$ tem até 27 anos, metade tem até 35 anos e cerca de $3 / 4$ tem até 45 anos.

A análise desagregada por faixa etária apenas confirma o diagnóstico apresentado anteriormente. Há forte concentração da faixa etária do MEI, na data de inscrição, entre 21 e 45 anos: praticamente $3 / 4$ estão na referida faixa etária (por volta de $74 \%$ ). Mais de 1/3 dos inscritos (33,98\%) tinham até 30 anos de idade e, como colocado anteriormente, metade dos inscritos tinha até 35 anos de idade. A faixa etária de 21 a 40 anos contempla cerca de 61,4\% dos inscritos.

Se for considerado que a carência da aposentadoria por idade é de 15 anos de contribuição, sendo concedida aos 65 anos de idade para os homens e aos 60 para as mulheres, poder-se-ia julgar que o programa seria mais atrativo para homens na faixa de 50 anos e para mulheres em torno de 45 anos que nunca haviam contribuído para a Previdência. Contudo, apenas 11,8\% dos inscritos tinham 51 anos ou mais.

Do ponto de vista das principais atividades, estavam: comércio varejista de artigos de vestuário e acessórios - comércio de roupa e confecção (220.829); cabeleireiros (157.568); comércio varejista de mercadorias em geral, com predominância de produtos alimentícios; serviços ambulantes de alimentação; comércio varejista de cosméticos, perfumaria e higiene pessoal; comércio varejista de bebidas; comércio varejista de artigos de armarinhos; confecção; outras atividades de tratamento de beleza; instalação e manutenção elétrica; serviços de pintura e outros; fornecimentos de refeições; alfaiataria; comércio de bijuterias; serviços de lava jato; serviços de lan house; fabricações de pães e bolos; serviços de borracharia etc. De modo geral, a predominância parece ser de trabalhadores por conta própria envolvidos em pequenas atividades comerciais, as mais variadas possíveis, bem como de serviços pessoais.

Em relação à forma de execução das atividades, cerca de $70 \%$ dos trabalhadores exerciam a atividade em domicílio. No tocante à forma de atuação: 58\% trabalhavam em estabelecimento fixo (inclusive no próprio domicílio); 20,3\% trabalhavam de porta em porta, em postos ou ambulantes; $6,7 \%$ trabalhavam pela Internet; além de outras formas de atuação.

A partir de dados da declaração anual dos MEI, foi mostrado que, em 2009, apenas 2,32\% dos declarantes tinham contratado empregados, percentual que se elevou 3,86\% em 2010. Portanto, embora seja permitido ao MEI contratar funcionário que ganha um salário mínimo ou o piso da categorial profissional, com

\section{Quadro 5: Estatísticas descritivas sobre idade do MEI}

\begin{tabular}{|l|r|r|r|r}
\hline \multirow{2}{*}{ Sexo } & \multicolumn{3}{c}{ Idade na Inscrição } \\
\cline { 2 - 5 } & \multicolumn{1}{c|}{ Quantidade } & \multicolumn{1}{c}{ Média } & \multicolumn{1}{c}{ Mediana } & \multicolumn{1}{c}{ Moda } \\
\hline Feminino & 773.870 & 36,66 & 35,00 & 30,00 \\
Masculino & 909,262 & 36,22 & 35,00 & 29,00 \\
\hline Total & $\mathbf{1 . 6 8 3 . 1 3 2}$ & $\mathbf{3 6 , 4 2}$ & $\mathbf{3 5 , 0 0}$ & $\mathbf{2 9 , 0 0}$ \\
\hline
\end{tabular}

Fonte: Elaborado pelo autor a partir de dados do Serpro e MDIC. 
contribuição patronal previdenciária reduzida para apenas 3\%, mesmo assim, a grande maioria não contrata empregados, pelo menos formalmente.

\section{Evolução da cobertura previden- ciária dos trabalhadores por conta própria}

Os dados da PNAD não permitem fazer uma análise de impacto do MEI na cobertura previdenciária dos trabalhadores por conta própria, tendo em vista que o último dado disponível é de setembro de 2009, quando o número de inscritos no programa era muito baixo e este não estava funcionando em nível nacional. A possibilidade que resta é analisar o incremento da contribuição previdenciária dos trabalhadores por conta própria por meio dos microdados da Pesquisa Mensal de Emprego (PME), que, se por um lado, apenas analisa algumas regiões metropolitanas, por outro lado, apresenta dados temporais com pequena defasagem no tempo.

Fazendo a análise por meio da evolução da contribuição previdenciária entre março de 2009 e março de 2011, pode-se notar, pelos dados do Quadro 6, que houve relevante incremento da contribuição previdenciária dos chamados trabalhadores por conta própria, tendo o percentual de contribuintes no referido período crescido de $20 \%$ para $24,3 \%$. Entretanto, esse incremento não pode ser atribuído diretamente ao MEI, pode ser efeito de outros fatores, mas, de qualquer forma, é indício de que o MEI pode ter tido impacto positivo.

Além disso, entre março de 2009 e março de 2011, o emprego com carteira de trabalho assinada, segundo dados da PME/IBGE, cresceu 14,4\%, tendo sido criados cerca de 1,5 milhão de empregos nessa modalidade. Portanto, como foi falado anteriormente, embora a expressiva geração de empregos formais não afasta por completo a ocorrência de substituição de emprego por MEI, certamente é indício de que isso não ocorreu em larga escala.

Houve, no mesmo período, uma redução de empregos sem carteira de trabalho assinada. Essa redução tanto pode ocorrer por transição de emprego sem carteira para emprego com carteira de

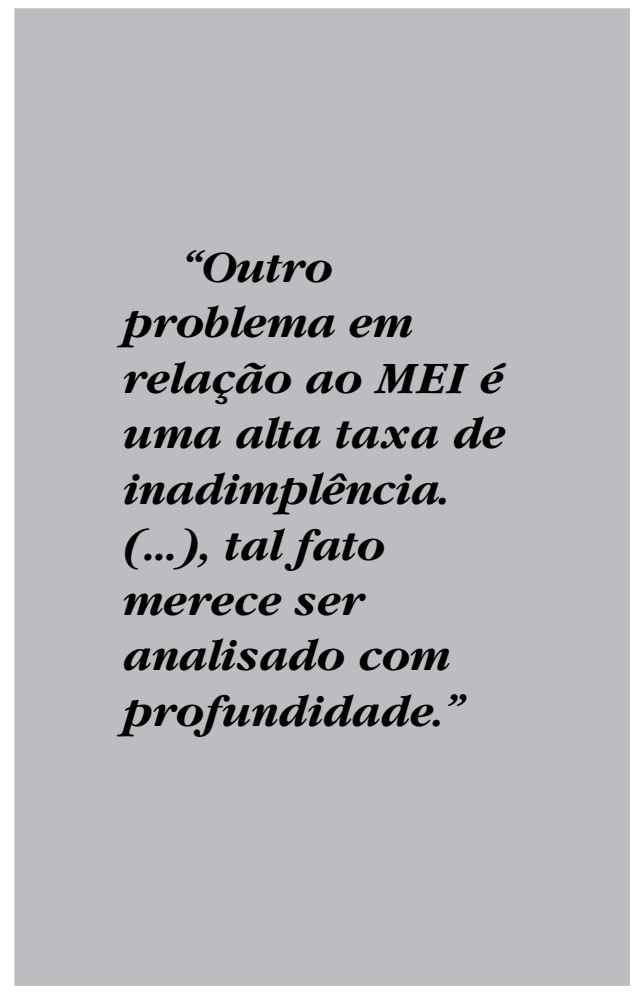

trabalho, como também haveria a possibilidade de migração de emprego informal para o MEI. Para ter certeza, torna-se necessária a análise das migrações.

\section{Considerações finais}

Aspecto fundamental dos mercados de trabalho dos países da América Latina, inclusive o Brasil, é o elevado grau de 
desproteção social ou previdenciária, que decorre, em grande parte, da alta taxa de informalidade prevalecente no mundo laboral. O cerne da desproteção engloba empregados e trabalhadores domésticos sem carteira de trabalho assinada, bem como os chamados trabalhadores por conta própria ou autônomos. $\mathrm{Na}$ realidade, parcela relevante dos trabalhadores por conta própria se insere, dessa forma, no mercado de trabalho não por opção, mas sim por necessidade e falta de outra alternativa de inserção. Portanto, trata-se muitas vezes de uma busca pela sobrevivência e geração de renda frente à incapacidade de inserção no mercado formal de trabalho.

Não em todos os casos essa inserção ocorre como reflexo de falta de alternativa, havendo, efetivamente, casos em que essa opção pode ser voluntária, ou seja, existe alguma heterogeneidade dentro desse grupo. De qualquer forma, o grau de cobertura previdenciária dos trabalhadores por conta própria é muito baixo e precário, sendo, inclusive, inferior ao dos trabalhadores domésticos; portanto, os chamados autônomos respondem por parcela significativa da desproteção previdenciária no Brasil. Nesse contexto, a ampliação da cobertura previdenciária passa, necessariamente, pela expansão da proteção social dos trabalhadores por conta própria.

Várias medidas foram tomadas nesse sentido, como a Lei n ${ }^{\circ} 10.666$, de 8 de maio de 2003, e a criação do chamado Plano Simplificado. Mais recentemente, foi instituído o chamado MicroEmpreendedor Individual (MEI), que aparentemente tem obtido resultados relevantes na ampliação da cobertura previdenciária, com a combinação de tratamento tributário diferenciado e condizente com a baixa capacidade contributiva do público-alvo, bem como

Quadro 6: Ocupados por situação de contribuição previdenciária PME/IBGE, março de 2009 e março de 2011

\begin{tabular}{|l|c|c|c|c|}
\hline Março de 2009 & $\begin{array}{l}\text { Ocupados com } \\
\text { contribuição } \\
\text { para } \\
\text { Previdência }\end{array}$ & $\begin{array}{l}\text { Ocupados não } \\
\text { contribuintes } \\
\text { para } \\
\text { Previdência }\end{array}$ & $\begin{array}{l}\text { Total de } \\
\text { ocupados }\end{array}$ & $\begin{array}{l}\text { Percentual de } \\
\text { contribuintes }\end{array}$ \\
\hline Empregados & 12.531 .147 & 3.375 .947 & 15.907 .094 & 78,8 \\
\hline Conta própria & 789.325 & 3.154 .590 & 3.943 .915 & 20,0 \\
\hline Empregadores & 633.294 & 328.109 & 961.403 & 65,9 \\
\hline $\begin{array}{l}\text { Trabalhadores } \\
\text { não remunerados }\end{array}$ & 0 & 140.254 & 140.254 & 0,0 \\
\hline Total & $\mathbf{1 3 . 9 5 3 . 7 6 6}$ & $\mathbf{6 . 9 9 8 . 9 0 0}$ & $\mathbf{2 0 . 9 5 2 . 6 6 6}$ & $\mathbf{6 6 , 6}$ \\
\hline Março de 2011 & $\begin{array}{c}\text { Ocupados com } \\
\text { Pontribuição para } \\
\text { Previdência }\end{array}$ & $\begin{array}{l}\text { Ocupados não } \\
\text { contribuintes } \\
\text { para Previdência }\end{array}$ & $\mathbf{0 c u p a d o s}$ & $\begin{array}{c}\text { Percentual de } \\
\text { contribuintes }\end{array}$ \\
\hline Empregados & 14.134 .957 & 3.121 .677 & 17.256 .634 & 81,9 \\
\hline Conta própria & 970.936 & 3.025 .856 & 3.996 .792 & 24,3 \\
\hline Empregadores & 607.011 & 314.595 & 921.606 & 65,9 \\
\hline $\begin{array}{l}\text { Trabalhadores } \\
\text { não remunerados }\end{array}$ & 753 & 103.406 & 104.159 & 0,7 \\
\hline Total & 15.713 .657 & 6.565 .534 & 22.279 .191 & 70,5 \\
\hline
\end{tabular}

Fonte: Elaborado pelo autor a partir dos microdados da PME/IBGE 
simplificação, desburocratização e oferta de benefícios aos que formalizarem, como crédito mais barato, maior acesso aos mercados por meio de notas fiscais e outros. Enfim, uma agenda que englobou ampliação da proteção social, racionalização da burocracia e estímulo aos microempreendedores.

A análise do perfil do MEI mostrou que, em geral, se trata predominantemente de homens jovens, com idade inferior a 45 anos e exercendo atividades comerciais e prestação de serviços.

Apesar do sucesso do programa, existem alguns cuidados e riscos que precisam ser minimizados, como a possibilidade de substituição de emprego por MEI, necessidades de avanços adicionais na simplificação das obrigações acessórias, maior envolvimento dos municípios na política etc. O controle do risco de mascarar uma relação de emprego pelo MEI está amenizado pelo fato de que não são todas as ocupações passíveis de serem inscritas como MEI, mas apenas cerca de 400 ocupações típicas de trabalhadores autônomos, conforme regulamentado pelo Comitê Gestor do Simples Nacional. O licenciamento dos municípios também deve funcionar como mecanismo de fiscalização. O forte crescimento do emprego formal em 2010 é indício de que não houve ocorrência desse problema em larga escala. Existe a possibilidade de substituição de emprego sem carteira por MEI.

Apesar desses cuidados, é preciso avaliar com rigor os resultados obtidos, analisando o passado contributivo (ou a falta dele) dos inscritos, em especial os obtidos com a Medida Provisória no 529/ 2011, que reduziu a contribuição de 11\% para 5\% do salário mínimo. Embora tal medida possa ter efeitos positivos do ponto de vista da ampliação da proteção social, também ampliou o desequilíbrio atuarial existente, bem como aumentou o risco de estimular a substituição de emprego por MEI. De qualquer forma, a redução para 5\%, exclusivamente do ponto de vista da inclusão previdenciária, pode ser considerada positiva e parece ter tido efeito positivo sobre as inscrições ao longo de 2011. Contudo, aparentemente, a referida medida não teve efeitos significativos na redução da inadimplência, e criou uma situação em que os benefícios são os mesmos do Plano Simplificado; mas o MEI paga 5\% do salário mínimo e o referido plano paga 11\%. Essa distorção deve provocar migração do Plano Simplificado para o MEI, bem como demandas de tratamento favorecido similar por parte de outros grupos.

Ponto importante a notar no desenho das políticas de ampliação da cobertura previdenciária é que, em um país como o Brasil, que tem uma complexa legislação trabalhista, previdenciária e tributária, com um conjunto muito grande de tratamentos diferenciados, qualquer desenho de política deve levar em consideração os incentivos que serão gerados do ponto de vista da arbitragem tributária.

Outro ponto importante é notar que as políticas de proteção social não podem ser pensadas separadamente daquelas voltadas ao mercado de trabalho. $\mathrm{Na}$ realidade, existe uma interrelação muito forte entre as políticas de proteção social e as de mercado de trabalho, de tal forma que ambas se afetam mutuamente. Infelizmente, é muito comum o desenho de políticas públicas sem levar em conta a forte interrelação entre essas políticas.

De qualquer forma, em que pese os riscos e problemas aqui salientados, é inegável que o MicroEmpreendedor Individual é uma política que pode ser 
considerada exitosa em vários sentidos: na ampliação da proteção social, no processo de simplificação e racionalização da burocratização, no registro de negócios formais e no apoio aos trabalhadores por conta própria informais (de baixa renda).
Contudo, é preciso um monitoramento contínuo e um aprofundamento da avaliação para o aperfeiçoamento dessa importante política pública.

(Artigo recebido em julho de 2011. Versão final em dezembro de 2011).

\section{Notas}

${ }^{1}$ Boletim Estatístico da Previdência Social, dezembro de 2011.

${ }^{2}$ Para uma análise detalhada desses impactos, ver Informe de Previdência Social de Abril de 2005 (publicação do Ministério da Previdência Social: Nova Metodologia para Contagem de Contribuintes Individuais.

${ }^{3}$ Endereço: portaldoempreendedor.gov.br

${ }^{4}$ Negativa quer dizer, no caso de não ter empregados.

${ }^{5}$ A isenção do MEI da chamada RAIS negativa foi instituída por meio da Portaria no 371 , de 24 de fevereiro de 2011 do Ministério do Trabalho e Emprego.

${ }^{6}$ Para uma análise mais detalhada ver o relatório do Fundo Constitucional de Financiamento do Centro-Oeste (FCO) - Programação para 2011. Ministério da Integração Nacional e Banco do Brasil.

${ }^{7}$ Os dados do MDIC diferem dos registros da Receita Federal pelo fato de considerar apenas as inscrições feitas no portal do empreendedor. A Receita Federal, além desses registros, considera a migração de empresas já existentes para o programa do MEI.

\section{Referências bibliográficas}

BrasiL. Decreto no 6.884, de 25 de junho de 2009. Institui o Comitê para Gestão da Rede Nacional para a Simplificação do Registro e da Legalização de Empresas e Negócios - CGSIM. Diário Oficial [da] Republica Federativa do Brasil, Brasília, DF, n. 120, p. 10-11, 26 jun. 2009. Seção 1.

Decreto no 3.048, de 06 de maio de 1999. Aprova o Regulamento da Previdência Social e dá outras providências. Diário Oficial [da] Republica Federativa do Brasil, Brasília, DF, n. 86, p. 1-109, 07 maio. 1999. Seção 1.

. Evolução Recente da Proteção Previdenciária e seus Impactos sobre o Nível de Pobreza. Brasília: MPS. v. 22, n. 10, 2010.

Lei $\mathrm{n}^{\circ}$ 8.212, de 24 de julho de 1991. Dispõe sobre a organização da Seguridade Social, institui Plano de Custeio, e dá outras providências. Diário Oficial [da] Republica Federativa do Brasil. Brasília, DF, n. 142, p. 14801, 25 jul. 1991. Seção 1. 
. Lei no 8.213, de 24 de julho de 1991. Dispõe sobre os Planos de Benefícios da Previdência Social, e dá outras providências. Diário Oficial [da] Republica Federativa do Brasil. Brasília, DF, p. 14.809, 25 jul., 1991. Seção 1.

. Lei n ${ }^{\circ}$ 10.666, de 08 de maio de 2003. Dispõe sobre a concessão da aposentadoria especial ao cooperado de cooperativa de trabalho ou de produção, e dá outras providências. Diário Oficial [da] Republica Federativa do Brasil. Brasília, DF, 09 maio 2003. Seção 1, p. 1.

. Lei n 11.598 , de 03 de dezembro de 2007. Estabelece diretrizes e procedimentos para a simplificação e integração do processo de registro e legalização de empresários e de pessoas jurídicas, cria a Rede Nacional para a Simplificação do Registro e da Legalização de Empresas e Negócios - REDESIM, e dá outras providências. Diário Oficial [da] Republica Federativa do Brasil. Brasília, DF, n. 232, p. 1, 04 dez. 2007. Seção 1. . Lei n $\mathrm{n}^{\circ}$ 12.470, de 31 de agosto de 2011. Altera os artigos 21 e 24 da Lei $\mathrm{n}^{\circ}$ 8.212, de 24 de julho de 1991, que dispõe sobre o Plano de Custeio da Previdência Social, e dá outras providências. Diário Oficial da União. Seção I. P. 1. (Publicação original).

. Lei Complementar no 123, de 14 de dezembro de 2006. Institui o Estatuto Nacional da Microempresa e da Empresa de Pequeno Porte, e dá outras providências. Diário Oficial [da] Republica Federativa do Brasil. Brasília, DF, n.240, p. 1, 15 dez. 2006. Seção 1.

. Lei Complementar $n^{\circ} 128$, de 19 de dezembro de 2008. Altera a Lei Complementar $n^{\circ} 123$, de 14 de dezembro de 2006, altera as Leis $n^{\text {os }} 8.212$, de 24 de julho de 1991, 8.213, de 24 de julho de 1991, 10.406, de 10 de janeiro de 2002 - Código Civil, 8.029, de 12 de abril de 1990, e dá outras providências. Diário Oficial [da] Republica Federativa do Brasil. Brasília, DF, n. 248, p. 1, 22 dez. 2008. Seção 1.

Lei Complementar no 139, de 10 de novembro de 2011. Altera dispositivos da Lei Complementar no 123 , de 14 de dezembro de 2006, e dá outras providências. Diário Oficial da União. Seção 1. P. 1. (Publicação Original).

. Medida Provisória no 529, de 07 de abril de 2009. Altera a Lei no 8.212, de 24 de julho de 1991, no tocante à contribuição previdenciária do microempreendedor individual. Diário Oficial [da] Republica Federativa do Brasil, Brasília, DF, n. 68, p. 1, 08 abr. 2011. Seção 1.

. Nova Metodologia para Contagem de Contribuintes Individuais. Brasília: MPS. v. 17, n. 4, 2005.

. Portaria do MTE n ${ }^{\circ}$ 371, de 24 de fevereiro de 2011. Dispõe sobre a dispensa da RAIS NEGATIVA para o MEI. Diário Oficial [da] Republica Federativa do Brasil, Brasília, DF, n. 68, p. 1, 08 abr. 2011. Seção 1.

. Resolução do MF/CGSN no 58, de 27 de abril de 2009. Dispõe sobre o Microempreendedor Individual - MEI no âmbito do Simples Nacional. Diário Oficial [da] Republica Federativa do Brasil, Brasília, DF, n. 79, p. 24-25, 28 abr. 2009. Seção 1.

. Resolução do MF/CGSN n. 78, de 13 de setembro de 2010. Altera a Resolução CGSN no 58, de 27 de abril de 2009. Diário Oficial [da] Republica Federativa do Brasil, Brasília, DF, n. 79, p. 35-40, 15 set. 2010. Seção 1.

Informe De Previdência Social. Cobertura Previdenciária: Evolução 1999-2002 e Aperfeiçoamento Metodológico. Brasília: MPS. v. 16, n. 5, 2004. 
Jaccoud, L. Pobres, Pobreza e Cidadania: os desafios recentes da proteção social. Texto para Discussão, Série Seguridade Social, IPEA, Brasília, n. 1.372, 2009.

Ministério da Integração Nacional. Fundo Constitucional de Financiamento do CentroOeste (FCO) - Programação para 2011 [online]. 2011. Disponível em: http:/ /www.mi.gov.br/ fundos / fundos_constitucionais / index.asp?area $=$ FCO $\% 20-\% 20$ Programa $\%$ E7\%E3o\%202011. Acesso em 15/03/2012.

Ranget, L. A. et al. Conquistas, Desafios e Perspectivas da Previdência Social no Brasil Vinte Anos Após a Promulgação da Constituição Federal de 1988. Políticas Sociais: acompanhamento e análise - Vinte Anos da Constituição Federal, IPEA, Brasilia, v. 1, n. 17, p. 58, 2009.

Serviço Brasileiro de Apoio a Micro E Pequena Empresa (Sebrae). 3 Anos da Lei Geral da micro e pequena empresa. Brasília, 2010. 


\section{Resumo - Resumen - Abstract}

\section{A experiência do microempreendedor individual na ampliação da cobertura previdenciária no Brasil}

Rogério Nagamine Costanzi; Edvaldo Duarte Barbosa e Hélio Vinícius Moreira Ribeiro

O mercado de trabalho brasileiro é caracterizado por elevada informalidade e por alto grau de desproteção previdenciária. Entre os principais componentes da referida desproteção estão os chamados trabalhadores por conta própria, que respondem por grande parcela do total de desprotegidos. Nesse sentido, a ampliação da cobertura passa, necessariamente, por medidas que ampliem a proteção social dos trabalhadores por conta própria. Já foram tomadas medidas no passado como, por exemplo, o Plano Simplificado, sem impacto significativo. Mais recentemente, foi instituído o Programa MicroEmpreendedor Individual, que, depois de dois anos do início do seu funcionamento em nível nacional, já registrava 2,1 milhões de adesões. O referido programa combina tratamento tributário diferenciado e favorecido; simplificação e racionalização da burocracia; apoio aos microempreendedores e benefícios pela formalização. $\mathrm{O}$ artigo apresenta a lógica do programa e sua evolução, bem como discute os riscos, cuidados e necessidades de avanços adicionais.

Palavras-chave: MicroEmpreendedor Individual; Proteção Social e Inclusão Previdenciária dos Trabalhadores por Conta Própria; Formalização

\section{La experiencia del microemprendedor individual en la ampliación de la cobertura previsional en Brasil}

Rogério Nagamine Costanzi; Edvaldo Duarte Barbosa y Hélio Vinícius Moreira Ribeiro

El mercado laboral brasileño se caracteriza por la informalidad y el alto grado de desprotección social. Entre los desprotegidos, se destacan los trabajadores por cuenta propia que representan gran parte de los trabajadores sin protección y, por lo tanto, son foco de importantes medidas de inclusión previsional. En 2007 fue instituido el Plan Simplificado. Sin embargo, el plan no ha logrado el éxito esperado. Recientemente, fue instituido un nuevo programa destinado a los Microemprendedores Individuales. El programa en poco más de dos años del inicio de las operaciones a nivel nacional ya había registrado 2,1 millones de inscripciones. El artículo presenta la lógica del programa y su evolución. Además, analiza los riesgos, los cuidados y las necesidades de nuevos avances.

Palabras clave: Microempreendedor Individual; Protección Social y Inclusión Previsional de los Trabajadores por Cuenta Propia o Autonomos; Formalización.

The role of small scale businesses in the expansion of access to social insurance in Brazil

\section{Rogério Nagamine Costanzi; Edvaldo Duarte Barbosa and Hélio Vinícius Moreira Ribeiro}

The Brazilian labour market is characterized by high informality and high levels of excluded workers of social security system. A major component of that deprotection is the called selfemployed workers, which account for a large portion of total unprotected. In this sense, the expansion of coverage needs measures to improve social protection of self-employed workers. Measures have been taken in the past like, for example, the Plan Simplified, without such a significant impact. More recently, a program called MicroEmpreendedor Individual was instituted at the national level. Two years after that there were 2,1 million subscribers. This program combines differential tax treatment, simplification and streamlining of bureaucracy and support and 
benefits to microentrepreneurs to formalize. The article presents the program logic and its evolution, and discusses the risks and the need for further enhancements.

Keywords: Microentrepreneur; Social Security Inclusion and Protection of Independent Workers; Formalization

\section{Rogério Nagamine Costanzi}

Mestre em Economia pela Universidade de São Paulo (USP). É Especialista em Políticas Públicas e Gestão Governamental, em exercício no Ministério da Previdência Social. Contato: rogerio.costanzi@previdencia.gov.br

Edvaldo Duarte Barbosa

Graduado em Engenharia Elétrica pela Universidade Federal do Rio Grande do Norte (UFRN). Auditor Fiscal da Receita Federal do Brasil, lotado no Ministério da Previdência Social, na Coordenação-Geral de Estudos Previdenciários.

Contato: edvaldo.barbosa@previdencia.gov.br

Hélio Vinícius Moreira Ribeiro

Bacharel em Estatística pela Universidade de Brasília (UnB). Atualmente trabalha como consultor em Estatística junto à Secretaria Nacional de Assistência Social, no Ministério do Desenvolvimento Social e Combate à Fome. Contato: vinicius2851982@gmail.com 